\title{
Multidisciplinary AEC Education Utilising BIM / PLIM Tools and Processes
}

\author{
Jennifer A. Macdonald ${ }^{1}$ and Marko Granroth ${ }^{2}$ \\ ${ }^{1}$ University of Technology, Sydney, Australia \\ ${ }^{2}$ KTH, Stockholm, Sweden \\ jennifer.macdonald@uts.edu.au
}

\begin{abstract}
The construction industry worldwide is moving towards more collaborative working practices, aided by building information modelling (BIM) tools and processes. BIM could be more accurately described as Project Lifecycle Information Management (PLIM). Many firms are claiming to be 'doing BIM', but are just scraping the surface in terms of the benefits that can be leveraged from true integrated, collaborative design and construction. New graduates, trained in collaboration and PLIM techniques will be the best people to drive positive change, but current educational models do not tend to provide these skills. This paper describes current worldwide educational trends in collaborative multidisciplinary education, and a proposed framework to assist academics in implementing changes to AEC curricula.
\end{abstract}

Keywords: Building Information Modelling; BIM; PLIM; construction education; collaborative working; BIM education and training; Framework.

\section{Introduction}

Faculties of the Built Environment (including architecture, engineering and construction management) are currently facing enormous changes due to disruptive technologies and processes emerging in both the higher education sector and the wider construction industry. Governments are demanding that Universities prove their worth as education providers and research generators in order to secure further public funding. At the same time, Universities in general are also facing pressure from the "Google Generation": the rise of Massive Open Online Courses (MOOCs) and other free or low-cost courses provided over the internet means that students have more choice in their courses and may be less willing to pay high fees for traditional chalk-and-talk transmission-style classes in Universities.

Faculties are also under pressure from a construction industry that is facing disruptive changes itself, due to the ongoing global financial crisis and the introduction of new technologies and processes heralded by the "BIM revolution." The current shortage of building design professionals trained in BIM remains a barrier to universal adoption of collaborative working practices in the industry. Just as industry must undergo a paradigm shift from its old combative culture to one of integration and information sharing, so must academia. The need for a framework to 
support adoption of collaborative design and BIM education by Architecture, Engineering and Construction (AEC) schools has been stated previously [1]. A framework (called the "IMAC Framework"), to support academics in adapting their curricula to include collaborative learning and working techniques, has been developed with the aid of an OLT (Australian Office of Learning and Teaching) grant. This paper discusses current trends in multidisciplinary AEC education and the progress of the IMAC trial in three Australian partner institutions.

\section{Innovation is Necessary for Survival in Industry and Education}

The global financial crisis has driven many businesses to the wall and many of the survivors have realised they need to innovate to win further work, and to be more efficient in the way they work in order to survive. Interestingly, this trend seems most apparent in countries whose economies, and construction industries, have been hardest hit (in the US and UK in particular) and less so in better-off economies such as Australia's [2]. This effect is illustrated by Teicholz' graph [3] (Fig. 1), which shows a moderate increase in real value added per US construction employee in the years after the 2007 downturn. However, the graph also illustrates the poor performance of construction compared to the manufacturing industry over the same period (the upper line indicates manufacturing). Even without factoring in the effects of the downturn, construction productivity has declined over the past 30 years [4].

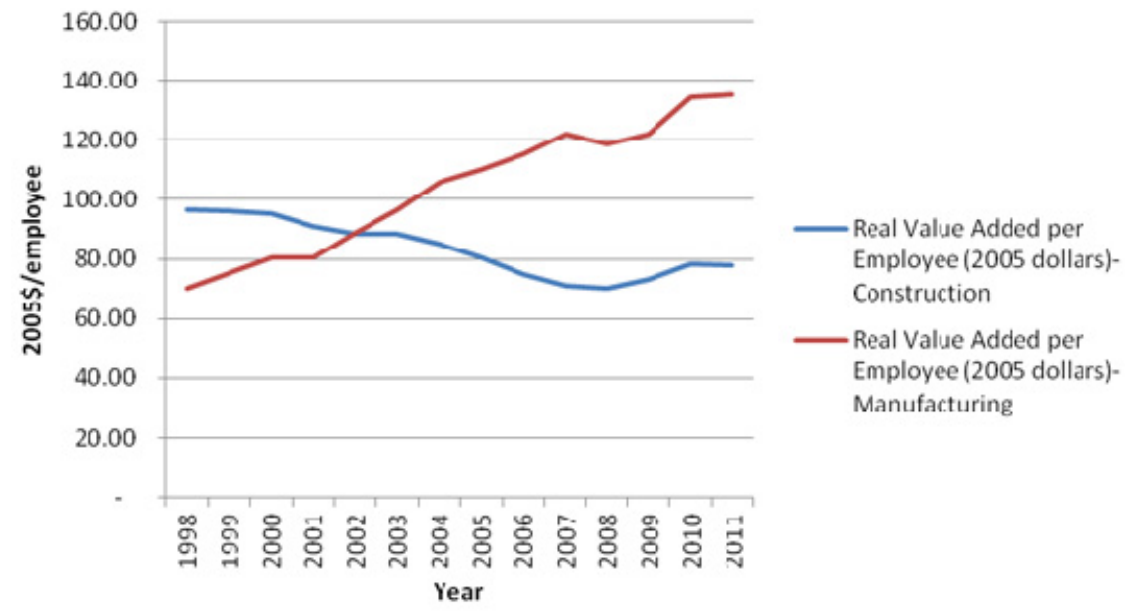

Fig. 1. Value Added per US Employee in 2005 dollars. Source: Teicholz [3]

The construction industry is extremely fragmented and lacking integration [5], [6]. Additionally, reports show that the quality of project documentation has declined over the past 20 years and that poor documentation is contributing an additional 10 to $15 \%$ to project costs. $60-90 \%$ of all variations are due to poor design and documentation 
[7]. It is worth noting, here, that the introduction of computer aided drafting (CAD) tools, far from improving the quality of documentation, has actually coincided with its decline.

In an attempt to achieve greater efficiencies, and echoing earlier changes adopted by the car and manufacturing industries, the construction industry worldwide is moving towards more collaborative working practices, aided by building information modelling (BIM) tools and processes. Collaboration between multidisciplinary, transglobal AEC teams is becoming commonplace [8]. Globalisation means that consultants can work from almost anywhere in the world and building elements can be prefabricated offshore and simply assembled on site. In the future, construction workers are likely to become assembly workers as prefabrication takes over. The increasing complexity of our buildings also means that our construction professionals must collaborate at earlier stages on jobs to produce the best result for clients. However, for the industry to move wholesale into integrated, collaborative practices, a seismic change is required in its culture. The culture of the construction industry has traditionally been very pugilistic, with minimal trust between parties on projects, aided by an atmosphere of litigation and punitive contracts. This lack of trust does not encourage information sharing and collaboration. Industry needs to move from the current culture of fragmentation, litigation, mistrust and withholding of information to one of open-ness, collaboration, teamwork and trust if it really wants to maximise the potential of BIM and improve overall productivity.

The current models for teaching students of the AEC disciplines do not support the new demands from both academia and industry. However, there is also a great opportunity to rethink the way AEC courses are developed and to become more efficient in delivering them. Holland [9] describes the need for "T-shaped people" in the construction teams of the future; that is to say people who have deep knowledge of their own professional discipline, but who also have broad knowledge of the other disciplines in the team.

\section{Defining BIM and PLIM}

The uptake of BIM has snowballed in recent years but at the same time "BIM" has become a fashionable marketing term, promoted by software vendors. Unfortunately, these vendors have led some professionals to think that to "do BIM" they simply have to purchase a 3D-rendering software package. Some industry figures have coined the term "BIMwash" to describe the phenomenon whereby many firms are claiming to be "doing BIM" but very few are using it to its full potential and integrating with all the other construction disciplines [10].

Despite the glossy marketing materials produced by various software manufacturers, there is still no universally accepted definition for BIM. BIM is not a software product, but an approach to creating and managing information about projects. Various sources suggest that the acronym originated in the US around 2002 [11], though, as stated previously, the tools and processes and ideas have been evolving since at least the 1970s and many of the processes mimic those adopted by 
the car industry decades ago, such as just-in-time manufacturing (JIT). . BIM can be a noun (the building information model) or a verb (the modelling process). Additionally, the individual words making up the acronym can mean different things to different professionals:

(B) Building can apply to a single building envelope or the wider built environment;

(I) Information is really the most important part of the acronym, as the concept is all about creating and sharing quality information about a project and not losing or recreating information when moving between phases;

(M) M originally stood for Modelling or Model but current literature tends towards the more appropriate definition of Management (e.g. Race, [12]).

The major problem with the term "building information modelling" is that it is inadequate for describing the complexity involved in creating and managing information over the lifecycle of construction projects, whatever their scale. Race [12] proposes borrowing from the acronym PLM (product lifecycle management) and replacing BIM with PLIM (Project Lifecycle Information Management), as this is a more accurate indication of the intent to create a comprehensive package of information representing the life of a facility.

\section{Overcoming the Status Quo}

"Many academic programs still produce students who expect they will spend their careers working as heroic, solitary designers. But integrated practice is sure to stimulate a rethinking of that notion. Pedagogy must focus on teaching not only how to design and detail, but also how to engage with and lead others, and how to collaborate with the professionals they are likely to work with later." Pressman [13], (p3)

Since engineering and architecture emerged as separate professional disciplines, AEC students have been educated in isolation from each other. Starzyk and McDonald [14] note that the focus of architectural education in the past was on developing individual skills such as being able to draw. Now, they state, "the importance of personal skill is yielding to the primacy of collective knowledge".

The complexity of modern building projects and technologies means that nobody can be a master of all anymore. Often the professions do not have a deep understanding of the information that each requires at different stages of a project. Time is thus wasted stripping out and even rebuilding models, when the models could have been set up more efficiently from the start of the process and unnecessary detail excluded prior to model exchange. If students are educated to work collaboratively and to learn the requirements of the other disciplines before they graduate, this level of misunderstanding is likely to be removed in future and trust improved. However, In order to bridge the disciplinary silos in industry, we need to start by breaking down the silos that exist in academia. 


\section{The Education vs. Training Debate}

The concept of creating job-ready graduates brings to the fore the "training vs. educating" debate. Traditionally, Universities have focused on teaching theory, with many faculty members believing that it is industry's role to train incoming graduates in job-related skills. The authors have frequently heard the refrain "we're not teaching students to press buttons" being used among educators who believe that BIM is just another CAD tool. However, the uptake of BIM is facilitating process, technological, and cultural changes, and its benefits extend far beyond mere visualization: students cannot be expected to "teach themselves BIM" any more than they could be expected to "teach themselves structural engineering". BIM actually provides a great opportunity to engage students more effectively and to aid understanding of how buildings are constructed. Hardy, quoted in Deutsch [15], (p202) states:

"When I look at the logic of construction means and methods that BIM inherently teaches, I see the potential to educate...”

Any major change process is likely to encounter resistance. Some of the difficulties for academia in introducing BIM may include:

1. Questions about how to fit new topics into a crowded curriculum.

2. Reluctance to change teaching habits established over many years.

3. For those who may have developed their own niche or expertise, there may be resistance to take on a new subject, about which they are not an expert, or to retrain in an area they are not familiar with.

4. As the technologies supporting BIM evolve at a rapid pace, academics who have been out of industry for some time may feel overwhelmed trying to keep abreast of them.

5. The traditional silos of architecture, engineering and construction schools can be difficult to bridge. As in industry, mistrust of the other professions also exists in academia, and questions can arise as to who is responsible for (and who will pay for) cross-disciplinary courses. "The biggest hurdle is with true interdisciplinary efforts due to conflicting student/faculty schedules and lack of compensation for more than one faculty member involved in a course" (Architectural Engineering Lecturer quoted in Vogt [16], p26)

6. Size of classes. Particularly in Australia, many academics face class minimum class sizes of 80 students, and the resources and time required to convert large cohort standard lecture-based courses into smaller multidisciplinary teamworkbased courses may seem an insurmountable challenge.

Motivation may also play a factor in the success of developing integrated curricula. The main motivation for industry to move towards collaborative working and the use of BIM has been pressure from major Clients and various governments, and the opportunity for improved profits and competitiveness. AEC educators are not generally subject to these same pressures. However, the construction industry has expressed a need for graduates skilled in collaborative building design and BIM. For 
example, BEIIC wrote to all the Deans of Australian Built Environment Faculties in June 2010 to enquire as "to what extent the universities are embracing new technologies such as BIM and equipping our future professionals with cutting edge experience." [17]. The Australian National BIM Initiative defines multi-disciplinary AEC education as one of six key areas needing support from both industry and government [18].

The AEC professional bodies are also beginning to apply pressure to academic institutions to develop integrated courses, through proposed changes to accreditation criteria. For example, the Australian Institute of Architects (AIA) and Consult Australia set up a joint BIM and IPD task force in 2012 [19], including a dedicated BIM in Education Working Group (of which the first author is a member).

\section{The CODE BIM Project}

The Australian Office of Learning and Teaching (OLT) has funded a project to develop a framework to assist AEC academics in introducing collaborative courses utilising BIM tools and processes. The Australian partner institutions in this project are the University of Technology, Sydney, the University of South Australia, and the University of Newcastle.

The initial stages of the project involved benchmarking current practice in academic institutions worldwide. According to Barison and Santos [20], the majority of US institutions (excepting pioneers such as Georgia Tech) began to introduce BIM in their courses from 2002, and it is a rapidly developing field. For example, Morse [21] lists eight US Academic Institutions and records survey responses from them indicating that $82 \%$ were providing formal teaching in BIM. A current web search reveals that $100 \%$ of the institutions listed by Morse now teach BIM in some of their courses, at least 17 of the 18 (94\%) ABET-accredited Architectural Engineering programs in the US now offer some level of BIM instruction, and at least 9 out of the 12 ABET accredited Construction Engineering institutions offer BIM courses (75\%).

To explore further the current practice and understanding of BIM and collaborative AEC education amongst AEC faculty, interviews were conducted with senior AEC academics and researchers from four leading Universities in Australia, three in the UK, one in Sweden, two in the Netherlands, one in Canada and five in the USA, over a period of two years. Some results of this study were reported previously [1]. In 2010, the first author was also involved in conducting a large on-line industry survey of AEC professionals and educators across Australia and New Zealand. The responses from the academic sector to this survey indicated that around $70 \%$ were using BIM at some level within their schools.

The most successful implementations of collaborative courses have been between Schools housed within the same financial unit (whether that is a faculty or department). For example, Penn State has implemented extremely successful capstone courses involving collaborative groups of students from its four architectural engineering disciplines, architecture and landscape architecture, as described by Solnosky et al. [22]. It appears that academics around the world face the same issues 
in relation to overcoming bureaucratic hurdles, such as which school pays for teaching of another school's students. Some schools have found that it is easier to develop collaborative courses between institutions than across faculties within their own institution. For example, the University of Southern California (USC) has run graduate-level courses with students from Virginia Tech and the University of Texas at Austin. Stanford University has collaborated with Twente University, Netherlands, to develop graduate-level courses in construction management with BIM support [23]. Other institutions have found that collaboration is easier when creating Masters-level courses, such as the Master of Design-Build program run jointly between Auburn University's Schools of Architecture and Building Science, and Salford University's Master of BIM and Integrated Design. So far, no University appears to have implemented fully collaborative courses across the three separate AEC disciplines at undergraduate level.

A striking difference observed between the US schools visited and those in Australia was typical class size. Class sizes continue to grow in Australia, boosted by the removal of government caps on entry numbers. However, staff numbers have not increased proportionally and it appears that many institutions have embraced larger and larger lecture-format classes to cope. BIM requires multidisciplinary collaboration, but it is very difficult to foster collaborative, technology-intensive teamwork in a classroom format consisting of a 3-hour weekly lecture to over 90 students. The largest multi-disciplinary class observed in the US contained 25 students, and some had as few as six.

Lectures, both physical and online, involve a transmission style of teaching that tends to focus on the lower levels of the taxonomy of learning proposed by Bloom et al [24]. Where small group, collaborative, problem-based learning approaches excel is in promoting the higher levels of learning in the taxonomies. Saljo [25] also defines deeper skills that students should develop, including making meaning and reinterpreting. The development of these types of skills is what Universities and other training providers should be focusing their efforts on. Transmission teaching just involves the broadcasting of data to a largely passive audience: knowledge cannot be transmitted into someone else's head.

\section{The IMAC Framework}

The development of the CODE BIM "IMAC" framework has been described in detail previously [26]. The framework comprises four key stages: Illustration, Manipulation, Application and Collaboration (IMAC). These stages do not necessarily always follow the years of a degree course, but can be viewed as building blocks of learning. The framework comprises two components: a benchmarking tool and a separate guide to implementation 


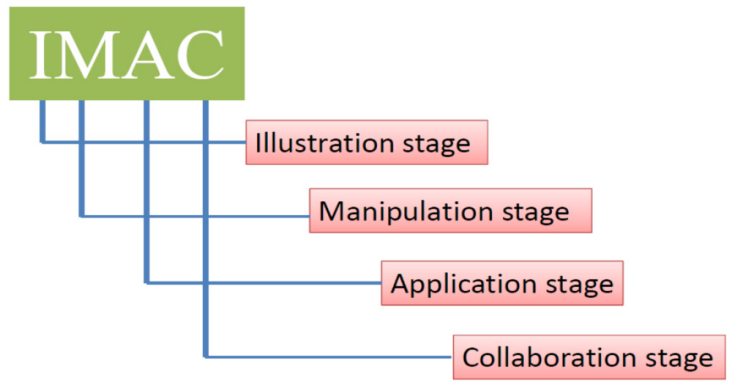

Fig. 2. The four stages making up the IMAC framework

The stages have been mapped to various levels on the taxonomy of learning proposed by Bloom et al [24] and expanded by Krathwohl et al [27]. As the IMAC framework aims to assist development of both technical (I.T and discipline-specific) and interpersonal (collaborative and teamwork) skills, it straddles the cognitive and affective domains.

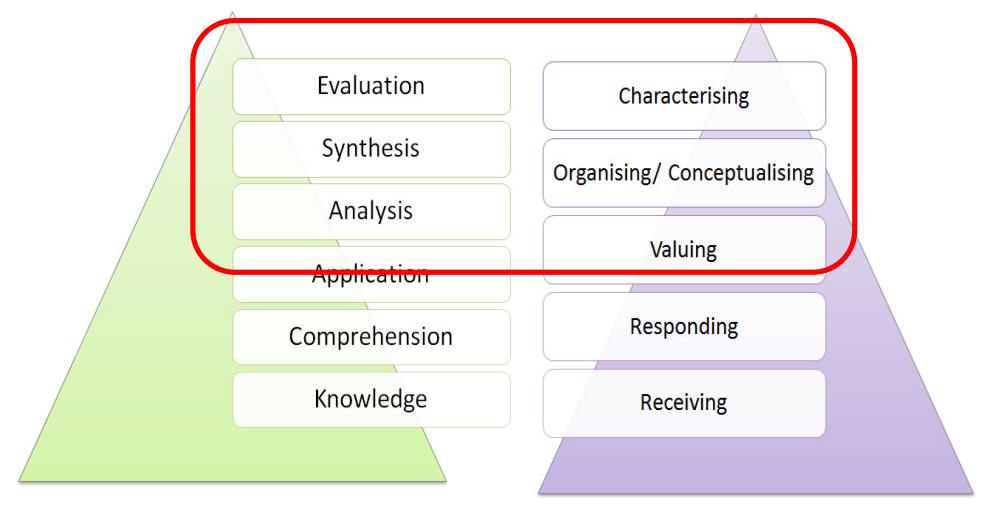

Fig. 3. Bloom's Taxonomy of Learning: Cognitive (L) and Affective (R) Domains [24],[27]

The framework does not dictate in which academic year each stage should be introduced. Students from the different AEC disciplines study courses of varying lengths and some skills are introduced earlier in some courses than others. For example, students of architecture tend to be introduced to modelling tools from first year whereas students of structural engineering might only be introduced to them in third year. It may also be possible to progress between stages within one academic year. The framework also considers suitable delivery methods at each stage, aiming to achieve deeper levels of learning as students progress through their education.

The benchmarking component of the IMAC framework has been used to benchmark existing courses at the three institutions and to plot targets for future curriculum developments. The framework recognises that the different disciplines will not be aiming to achieve full collaboration in all courses or areas - for example, architecture graduates will be expected to be able to create full BIM models from 
scratch whereas engineers and construction managers would usually only be expected to be able to manipulate existing models for their own analysis purposes. The framework tool thus suggests different targets (shaded, refer Fig 4) for the different discipline areas, and it is expected that these will be mapped to professional accreditation criteria as these are developed.

\begin{tabular}{|c|c|c|c|c|c|c|c|c|c|c|c|}
\hline & $\begin{array}{c}\text { BUILDING } \\
\text { TECHNOLOGY }\end{array}$ & \multicolumn{2}{|c|}{ ENVIRONMENT } & \multicolumn{3}{|c|}{ MANAGEMENT } & \multicolumn{2}{|c|}{ IT } & \multicolumn{3}{|c|}{ SPECIALISM } \\
\hline & Framing & Matenals & Sustainability & People & Communication & Teamwork & $\begin{array}{c}\text { General } \\
\text { IT }\end{array}$ & $\begin{array}{l}\begin{array}{l}\text { BIM } \\
\text { tools }\end{array} \\
\text { to }\end{array}$ & A & $\mathrm{E}$ & $\mathrm{c}$ \\
\hline \multicolumn{12}{|l|}{ Collaboration } \\
\hline \multicolumn{12}{|l|}{ Application } \\
\hline \multicolumn{12}{|l|}{ Manipulation } \\
\hline \multicolumn{12}{|l|}{ Illustration } \\
\hline 0 Not Used & & & & & & & & & & & \\
\hline
\end{tabular}

Fig. 4. IMAC chart for an Engineering Course (suggested Target Levels shaded

The project considers two separate aspects of collaboration: collaborative working and collaborative learning. Collaborative working involves student teams tackling project-based tasks that simulate the new collaborative industry working practices. In other words, they are collaborating to achieve a goal (e.g. the design of a building). By contrast, for collaborative learning it is the learning itself that is the goal. There is a large body of pedagogical research showing that students engage and learn much better through teamwork and team learning. The Stoic philosopher Seneca stated that, "by teaching we learn", and the theory that students learn more from teaching has been proven through research [28], [29]. The teacher acts more like a peer in the collaborative environment.

\section{Conclusions and Some Proposals}

In response to some of the questions raised earlier in this paper, integrating principles of collaboration and BIM technologies into existing classes throughout the curriculum should reduce the need to develop completely new courses. Bolt-on capstone courses, though useful as a first foray into collaborative courses, do not constitute curriculum renewal. In order to encourage true curriculum renewal, the professional bodies should update their accreditation criteria to reflect the industry need for graduates skilled in BIM and collaborative working. Accreditation criteria provide the greatest incentive for academic institutions to instigate changes to their curricula.

Ironically, the industry problem that is creating huge demand for BIM-related courses is also one that affects employers of academics: how to recruit (or train) and then retain teaching staff skilled in the areas of collaborative working and BIM 
technologies? This is a particularly difficult question given the high demand, and consequently high salaries, on offer in industry. Many universities are reliant on assistance from guest tutors from industry when introducing technical courses in BIM, but it would be wise for these institutions to develop strategies to capture this external knowledge and train faculty members in addition to their students. AEC education should perhaps take its cue from the construction industry by looking at ways to become more efficient and collaborative. Why, for example, should institutions not pool their resources for the teaching of lower level courses and use their valuable faculty to deliver more intensive courses at higher levels? For example, engineering mathematics and statistics classes tend to cover the same content all over the world. An excellent lecturer could be nominated from one institution to provide a definitive online course on one topic that students in all engineering courses are required to pass in their own time before progressing to more advanced in-class courses. This is not really too dissimilar to many institutions setting textbooks that have been written by academics in other universities.

The authors have attended many BIM workshops and conferences over the past few years and it seems that general questions from industry have moved on from "what is BIM and why should we adopt it?" to "we accept that we need to adopt BIM, now how do we go about doing so?" Although AEC academics (with notable exceptions) generally appear to be at the earlier stage of questioning, it is likely that they will also move towards the question of implementation, and the framework described should provide assistance in this. The future belongs to the integrators!

"I am looking for a lot of men who have an infinite capacity to not know what can't be done..." [Henry Ford]

The Benchmarking component of the IMAC tool is has been trialed at the three partner institutions in the CODE BIM project and observational studies of collaborative classes developed using the tool are being carried out over the 2013 study year. It is expected that the results of the trial and classroom studies will be published towards the end of the year, as will the final CODE BIM framework tools, via the project website (www.codebim.com).

Acknowledgments. The first author acknowledges the support provided by the Office of Learning and Teaching (OLT) under OLT Priority Project Code PP10-1745, and by UTS through a Teaching Fellowship Award, which enabled research to be conducted in the overseas institutions described. Further details of the CODE BIM project can be viewed at www.codebim.com

\section{References}

1. Macdonald, J.A., Mills, J.E.: The Potential of BIM to Facilitate Collaborative AEC Education. In: Proceedings of the 118th ASEE Annual Conference, American Society of Engineering Education. Vancouver, Canada (June 2011)

2. Allen Consulting Group: Productivity in the buildings network: assessing the impacts of Building Information Models, report to the Built Environment Innovation and Industry Council, Sydney (October 2010) 
3. Teicholz, P.: Labor-Productivity Declines in the Construction Industry: Causes and Remedies (Another Look). AECbytes Viewpoint (67) (March 14, 2013)

4. Teicholz, P.: Labor productivity declines in the construction industry: causes and remedies. AECbytes Viewpoint (4) (April 14, 2004)

5. NIST (National Institute of Standards and Technology), Cost Analysis of Inadequate Interoperability in the U.S. Capital Facilities Industry. NISTGCR 04-867. NIST, Gaithersburg (2004)

6. Wolstenholme: Never Waste a Good Crisis: A Review of Progress since Rethinking Construction and Thoughts for Our Future, Constructing Excellence (October 2009), http://www.constructingexcellence.org.uk/pdf/Wolstenhome_Rep ort_Oct_2009

7. QCIF (Queensland Construction Industry Forum), Getting it Right First Time (2005)

8. O'Brien, W., Soibelman, L., Elvin, G.: Collaborative Design Proceses: An Active- and Reflective- Learning Course in Multidisciplinary Collaboration. Journal of Construction Education 8(2), 78-93 (2003)

9. Holland, R., Messner, J., Parfitt, K., Poerschke, U., Pihlak, M., Solnosky, R.: Integrated Design Courses Using BIM as the Technology Platform. In: Annual Meeting of EcoBuild America Conference, Washington, DC, December 7. National Institute of Building Sciences (2010)

10. Miller, R.: The BIM Mirage or BIMwashing, online blog entry in The Commercial Real Estate Revolution (October 2009), http://thecrerevolution.com/2009/ $10 /$ the-bim-mirage-or-bimwashing/

11. Eastman, C., Teicholz, P., Sacks, R., Liston, K.: BIM Handbook: A Guide to Building Information Modeling for Owners, Managers, Designers, Engineers, and Contractors. John Wiley \& Sons, Inc., New Jersey (2008)

12. Race, S.: BIM Demystified: An Architect's guide to Building Information Modelling/Management (BIM). RIBA Publishing, London (2012)

13. Pressman, A.: Integrated Practice in Perspective: A New Model for the Architectural Profession, Architectural Record (May 2007),

http: //archrecord.construction.com/practice/projDelivery/ 0705 proj-3.asp

14. Starzyk, G.F., McDonald, M.: The Collaborative Dance: Only Three Steps. In: Salazar, G., Issa, R. (eds.) Proc. of the BIM-Related Academic Workshop, Washington, DC, December 7-9 (2010)

15. Deutsch, R.: BIM and Integrated Design: Strategies for Architectural Practice. John Wiley \& Sons, Inc., New Jersey (2011)

16. Vogt, B.A.: Relating Building Information Modeling\& Architectural Engineering Curricula, Department of Architectural Engineering, Kansas State University, MSc Thesis (2010)

17. BEIIC, Letter to all Deans of Australian Built Environment Faculties (2010) (unpublished)

18. BuildingSMART, The National BIM Initiative, Report to DIISRTe (June 2012), http: / /buildingsmart.org.au/nbi-folder/ NationalBIMIniativeReport_6June2012.pdf

19. AIA, BIM and IPD Steering Committee. Documents produced by the four working groups (2012), http: / / www.bim.architecture.com.au/groups /

20. Barison, M.B., Santos, E.T.: BIM teaching strategies: an overview of the current approaches. In: Proc. of the International Conference on Computing in Civil and Building Engineering, Nottingham (2010) 
21. Morse, E.J.: An Online Case Study Resource for Building nformation Modeling in College Education (Worcester Polytechnic Institute) (2009), http: / /www.wpi.edu/Pubs / E-project/Available/E-project-090109-010641/unrestricted/ EJM-BIMinEducation.pdf

22. Solnosky, R., Parfitt, M., Holland, R.: An IPD and BIM Focused Capstone Course Based on AEC Industry Needs and Involvement. J. Prof. Issues Eng. Educ. Pract. (February 28, 2013) doi: 10.1061/(ASCE)EI.1943-5541.0000157

23. Peterson, F., Hartmann, T., et al.: Teaching construction project management with BIM support: Experience and lessons learned. Automation in Construction 20, 115-125 (2011)

24. Bloom, B.S., Englehart, M.D., Furst, E.J., Hill, W.H., Krathwohl, D.R.: The Taxonomy of Educational Objectives, The Classification of Educational Goals, Handbook I: Cognitive Domain. David McKay Company, New York (1956)

25. Säljö, R.: Learning in the learner's perspective: 1. Some common-sense conceptions. Reports from the Institute of Education, University of Gothenburg, 76 (1979)

26. Macdonald, J.A.: A framework for collaborative BIM education across the AEC disciplines. In: 37th Annual Conference of Australasian University Building Educators Association (AUBEA), Sydney, Australia, July 4-6 (2012)

27. Krathwohl, D.R., Bloom, B.S., Masia, B.B.: The Taxonomy of Educational Objectives: The Classification of Educational Goals, Handbook II: Affective Domain. David McKay Company, New York (1964)

28. Annis, L.F.: The process and effects of peer tutoring. Human Learning 2, 39-47 (1983)

29. McKeachie, W.J., Pintrich, P.R., Lin, Y.-G., Smith, D.A.F.: Teaching and Learning in the College Classroom: A Review of the Research Literature. University of Michigan, National Center for Research to Improve Postsecondary Teaching and Learning, Ann Arbor (1986) 